\title{
Incidence and Risk Factors of Morbidely Adherent Placenta in Cases with Previous Caesarean Section in Benha University Hospital
}

S.A.Elbery , M.A.Mahmoud, A.E.Mansour, M.F.Rashed and H.E.Salem

Obstetrics and Gynecology Dept., Faculty of Medicine, Benha Univ., Benha, Egypt

E-Mail: dr.hebasalem2010.com@gmail.com

\begin{abstract}
Morbidly adherent placenta (MAP) is defined as the abnormal adherence of placenta to the underlying uterine wall. Strange placental adherence can be grouped into three particular conditions: placenta accreta; placenta increta, and placenta percreta where chorionic villi infiltrate through the uterine serosa and may attack encompassing. The points of this examination were to decide the occurrence of sullenly Adherent Placenta in cases with past cesarean segment in Benha University from December 2018 till June 2019.Also to decide the epidemiological elements in instances of Morbidly Adherent Placenta according to ordinary placenta. The imminent examination was done at Benha University Hospital, from December 2018 till June 2019 where a sum of 33 ladies who satisfied the consideration standards were enlisted into the investigation. Coming up next were accomplished for all case: history, clinical assessment and ultrasonography assessment. Level of Morbidity Adherent Placenta was (36.4\%).Percentage of Accreta (18.2\%), Focal Accreta (3.0\%), Percreta $(15.2 \%)$. There were measurably critical increment in Number of Previous CS among cases with Morbidly Adherent Placenta than cases without Morbidly Adherent Placenta.There were factually noteworthy increment in Gravidity (frail) and Parity and maternal age among cases with Morbidly Adherent Placenta than cases without Morbidly Adherent Placenta. Ladies with an earlier cesarean conveyance had a high frequency of MAP. The most common sullen bond was placenta accumulate. Expanded frequency of MAP with expanding number of past cesarean conveyances. There was additionally an expanded danger of MAP related with more seasoned maternal age. Multiparity and multigravidas have been proposed as being related with a higher danger of MAP.
\end{abstract}

Keywords: Morbidly adherent placenta. Previous cesarean section. Incidence. Risk factors.

\section{Introduction}

Dismally follower placenta (MAP) is characterized as the irregular adherence of placenta to the fundamental uterine divider. It is grouped by the level of entrance, into 3 sorts: Placenta accretachorionic villi is disciple to shallow myometrium, Placenta increta-chorionic villi reaches out into the myometrium and Placenta percretachorionic villi infiltrating full thickness myometrium and including serosa and may include adjoining organs like urinary bladder [1].

Irregular placental adherence can be grouped into three unmistakable conditions: placenta accreta, in which placental tissue attacks the decidual surface of the myometrium; placenta increta, in which placental villi attack all the more profoundly inside the myometrium, and placenta percreta where chorionic villi enter through the uterine serosa and may attack encompassing organs, for example, the bladder [2].

Placenta accreta range (PAS) issue have become a noteworthy dangerous obstetrical issue because of its expanded rate from 0.12 to $0.31 \%$ in the last 30 years and the detailed death pace of roughly $7.0 \%$. Moreover, it is identified with extensive maternal grimness which incorporates huge blood transfusion, urinary tract injury, hysterectomy, admission to emergency unit confirmation, sepsis, and long medical clinic remain. The term PAS alludes to variable degrees of adherence and intrusion of the uterus and/or encompassing organs by the placenta, for example placenta accreta, increta and percreta which hinder the placental detachment at conveyance and could therefore bring about extensive maternal discharge that hazard the life of both the mother and the neonate [3].
As of late, a few investigations have attempted to recognize the hazard factors for PAS issue, it has been accounted for that maternal age ( $\geq 35$ years) and placenta previa were fundamentally connected with the improvement of PAS issue. In like manner, progressed maternal age and expanded number of past CSs were free hazard factors for PAS issue [4].

The perfect administration approach for PAS issue is questionable. The American College of Obstetricians and Gynecologists (ACOG) suggests elective CS hysterectomy with the placenta set up as expulsion of the placenta in these cases prompts gigantic blood misfortune. This choice might be not acknowledged in cases wishing to protect their ripeness. In such cases, moderate administration ought to be considered after appropriate guiding in regards to dangers [5].

The points of this examination were to decide the rate of dismally Adherent Placenta in cases with past cesarean area in Benha University from December 2018 till June 2019.Also to decide the epidemiological elements in instances of Morbidly Adherent Placenta according to typical placenta.

\section{Patients and methods}

This prospective study carried out at Benha University Hospital, from December 2018 till June 2019 where a total of 33 women who fulfilled the inclusion criteria enrolled into this study.

\subsection{Ethical considerations}

The study was approved by the Ethics Committee of the Faculty of Medicine, Benha University. Informed consent was obtained from each participant before study start. 


\subsection{Inclusion criteria are}

Patients with prior cesarean deliveries.

\subsection{Exclusion criteria}

- Patients with unscarred uterus.

- Primigravida.

\subsection{Methodology}

1- An informed consent was obtained before scanning and a written consent was signed for the management.

2- History taking

- Full history (name, age, file number, Most responsible physician/contacts).

- Obstetric history (number of CS, abortion, placenta previa in previous pregnancy, history of ectopic, medical disorder with previous pregnancy, number of living children, Interval between previous section and current pregnancy).

- Present history (complain, gestational age, no medical disorder in present pregnancy, BMI, history of antepartum hemorrhage).

- Past history (postpartum sepsis, postpartum hemorrhage, chronic diseases, place of previous cesarean section, Hospital staying, need of blood transfusion, condition of previous surgery if emergency or elective, Previous ANC \{IUCD, APH, Abortion $\},$ ART $\{$ IUI,ICSI $\}$ )

- History of myometrial injuries as: (myomectomy, extensive uterine curettage, and hysteroscopic surgery).

\section{3- Examination}

- General.

- Abdominal.

4- Investigations

- Laboratory tests: Preoperative \& postoperative (CBC, INR), liver and kidney function tests, FBS \& $2 \mathrm{~h} \mathrm{pp).}$

- Ultrasonography:

- Complete imaging using (gray-scale ultrasonography and color Doppler).

- For each patient, the whole placenta was scanned in a systematic fashion using both gray-scale ultrasound and color flow mapping. The placenta was imaged with a sufficient bladder volume to clearly visualize the serosa-bladder interface the flow within the abnormal lacunae and any newly formed vessels over the serosa-bladder border was measured.

On gray-scale ultrasound imaging, we considered the presence of at least one of the following characteristics indicates placenta accreta (including its variants, placenta increta and placenta percreta):

1- Complete loss of the hypo-echoic retroplacental sonolucent zone.

2- Irregular retroplacental sonolucent zone.

3- Thinning of the hypoechoic retroplacental myometrium to $<2 \mathrm{~mm}$.
4- Thinning or disruption of the hyperechoic uterine serosa-bladder interface.

5- Presence of focal exophytic masses invading the urinary bladder.

6-Presence of abnormal placental lacunae[6].

Likewise, the diagnosis of placenta accreta was regarded as positive when any one of these color Doppler criteria is present:

1- Diffuse or focal lacunar flow pattern.

2- Sonolucent vascular lakes with turbulent flow.

3- Hypervascularity of the uterine-bladder interface with abnormal blood vessels linking the placenta to the bladder.

4- Markedly dilated vessels over the peripheral subplacental region [7].

\section{5- The management}

All the pregnant patients enrolled in this study was delivered by laparotomy. All was done at our hospital with full availability of information on the delivery after a written consent before operation. Definitive diagnosis of placenta accreta was made at delivery when the myometrium was seen to be invaded by the placenta and the histopathological examination of the uterus.

\section{6- Intraoperative data}

- Placental site, spontaneous separation, placental invasion into the bladder and other surrounding organs.

- Blood loss and blood transfusion.

- Conservative management versus hysterectomy.

\section{7- Postoperative data:}

- Intensive care unit admission.

- Postoperative hemoglobin.

- Postoperative INR.

- Postoperative platelet.

- Postoperative blood transfusion.

- The need of exploration after surgery

8- The histopathological criteria for diagnosing abnormal placenta include:

a. Placenta accreta: microscopically, the placental villi interdigitate directly with the uterine myometrium and invading less than half of myometrium.

b. Placenta increta: the placental villi invading more than half of myometrium but not reaching the serosa.

c. Placenta percreta: the placental villi invading more than half of myometrium reaching the serosa and may invade near organs specially the base of the bladder [8].

\subsection{Statistical analysis}

The data were coded, entered and processed on computer using SPSS (version 23). The results were represented in tabular and diagrammatic forms then interpreted. 
Mean, standard deviation, range, frequency, and percentage were use as descriptive statistics. The following test was done: Chi-Square test $\mathrm{X}^{2}$.Student's ttest. $\mathrm{P}$ value was considered significant as the following: $\mathrm{P}>0.05$ : Non significant.P $\leq 0.05$ : Significant

Mean of Gravidity $(3.85 \pm 1.395)$, Parity $(2.82 \pm$ 1.402), Age (31.33 \pm 5.212$)$, G.A $(34.42 \pm 3.553)$, the percentage of $<25(72.7 \%),>30(12.1 \%), 25-30(15.2 \%)$ Table (1).

Mean of Number of Previous c.s (2.30 \pm 1.075$)$, Mean of Interval between Previous c.s And current preg $(3.85 \pm 2.946)$. The percentage of History of Previous CS (100\%), wound infection of Previous CS (6.1 \%), Previous abortion (12.2\%), according to Place of Previous CS the percentage of center $(60.61 \%)$, hospital (39.39\%), according to Type of operation of Previous CS the percentage of cs (97\%), hysterectomy (3\%), according to Inter operative complication of Previous CS the percentage of Rupture uterus (3\%), Bladder injury $(0 \%)$, Bowel injury (0\%) Table (2).

The percentage of Morbidly Adherent Placenta (36.4\%), No Morbidly Adherent Placenta (63.6\%) Table (3).

The percentage of Accreta (18.2\%), Focal Accreta (3.0\%), Percreta (15.2\%) Table (4).
There was no statistically significant difference between cases with Morbidly Adherent Placenta and cases without Morbidly Adherent Placenta regarding Age (years), G.A and BMI. There were statistically significant increase in Gravidity (weak) and Parity among cases with Morbidly Adherent Placenta than cases without Morbidly Adherent Placenta Table (5)

There were statistically significant increase in Number of Previous c.s and Interval between Previous c.s and current preg among cases with Morbidly Adherent Placenta than cases without Morbidly Adherent Placenta. There was statistically significant difference between cases with Morbidly Adherent Placenta and cases without Morbidly Adherent Placenta regarding previous abortion and wound infection of Previous CS Table (6).

There was no statistically significant difference between cases with Morbidly Adherent Placenta and cases without Morbidly Adherent Placenta regarding RH.There were statistically significant increase in Blood transfusion (numbers of packs of blood) and $\mathrm{Hb}(\mathrm{g} / \mathrm{dl})$ among cases with Morbidly Adherent Placenta than cases without Morbidly Adherent Placenta Table (7).

\section{Results}

Table (1) Demographic data of the studied cases.

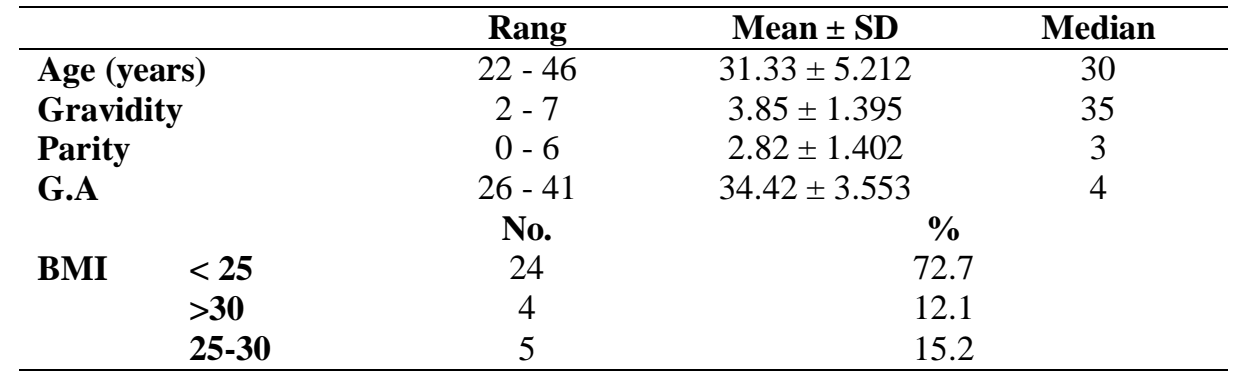

Table (2) CS among the studied cases.

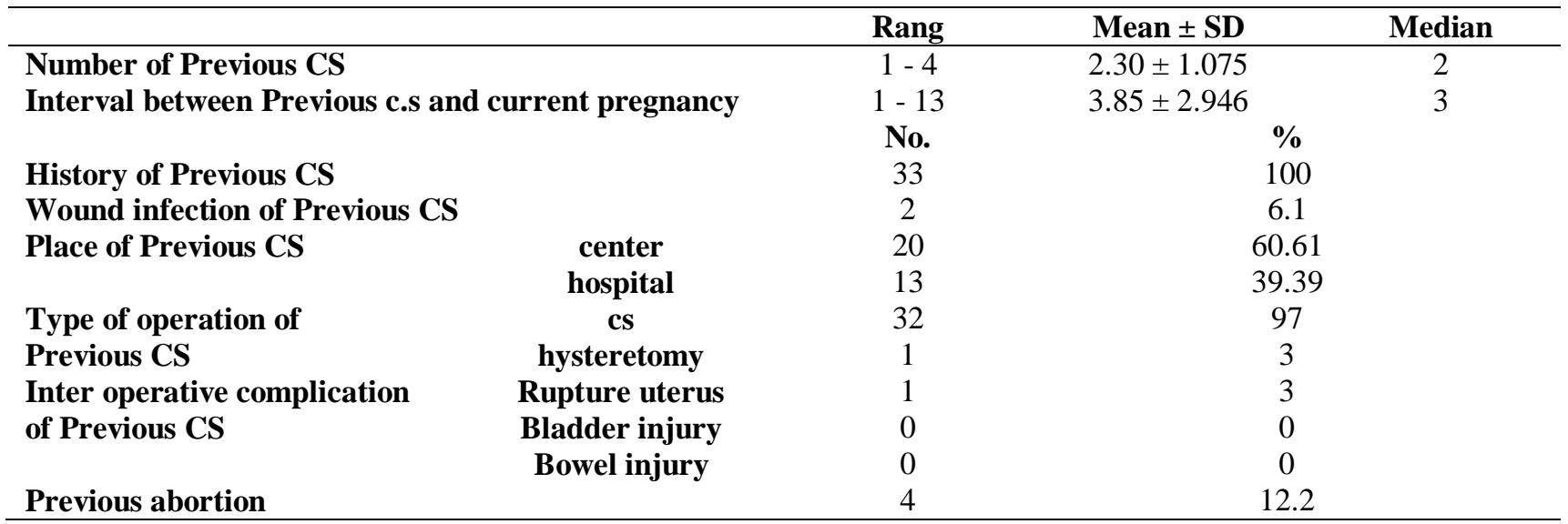

Table (3) Morbidly Adherent Placenta among the studied cases.

\begin{tabular}{llcc}
\hline & & No. & $\%$ \\
\hline Morbidly Adherent & Morbidly Adherent Placenta & 12 & 36.4 \\
Placenta & No Morbidly Adherent Placenta & 21 & 63.6 \\
\hline
\end{tabular}


Table (4) Type of morbidly Adherent Placenta among the studied cases.

\begin{tabular}{lccc}
\hline & & No. & $\%$ \\
\hline Type of Morbidly Adherent & Accreta & 6 & 18.2 \\
Placenta & Focal Accreta & 1 & 3.0 \\
& Percreta & 5 & 15.2 \\
\hline
\end{tabular}

Table (5) Comparison between cases with Morbidly Adherent Placenta and cases without Morbidly Adherent Placenta regarding Demographic data.

\begin{tabular}{|c|c|c|c|c|c|c|}
\hline & & & $\begin{array}{c}\text { Morbidly Adherent } \\
\text { Placenta }\end{array}$ & $\begin{array}{c}\text { No Morbidly } \\
\text { Adherent Placenta }\end{array}$ & $\mathbf{X}^{2}$ & P. value \\
\hline Gravidity & \multicolumn{2}{|c|}{ Mean \pm SD } & $4.08 \pm 1.621$ & $3.71 \pm 1.271$ & .726 & 0.047 \\
\hline Parity & \multicolumn{2}{|c|}{ Mean \pm SD } & $3.17 \pm 1.586$ & $2.62 \pm 1.284$ & 1.082 & 0.032 \\
\hline Age (years) & \multicolumn{2}{|c|}{ Mean \pm SD } & $32.00 \pm 6.135$ & $30.95 \pm 4.727$ & 0.549 & 0.587 \\
\hline G.A & \multicolumn{2}{|c|}{ Mean \pm SD } & $33.92 \pm 4.055$ & $34.71 \pm 3.304$ & $-0.614-$ & 0.544 \\
\hline \multirow[t]{3}{*}{ BMI } & $<25$ & $\begin{array}{c}\text { No. } \\
\%\end{array}$ & $\begin{array}{c}9 \\
75.0 \%\end{array}$ & $\begin{array}{c}15 \\
71.4 \%\end{array}$ & 0.265 & 0.876 \\
\hline & $>\mathbf{3 0}$ & $\begin{array}{l}\text { No. } \\
\%\end{array}$ & $\begin{array}{c}1 \\
8.3 \%\end{array}$ & $\begin{array}{c}3 \\
14.3 \%\end{array}$ & & \\
\hline & 25-30 & $\begin{array}{l}\text { No. } \\
\%\end{array}$ & $\begin{array}{c}2 \\
16.7 \%\end{array}$ & $\begin{array}{c}3 \\
14.3 \%\end{array}$ & & \\
\hline
\end{tabular}

Table (6) Comparison between cases with Morbidly Adherent Placenta and cases without Morbidly Adherent Placenta regarding $\mathrm{CS}$.

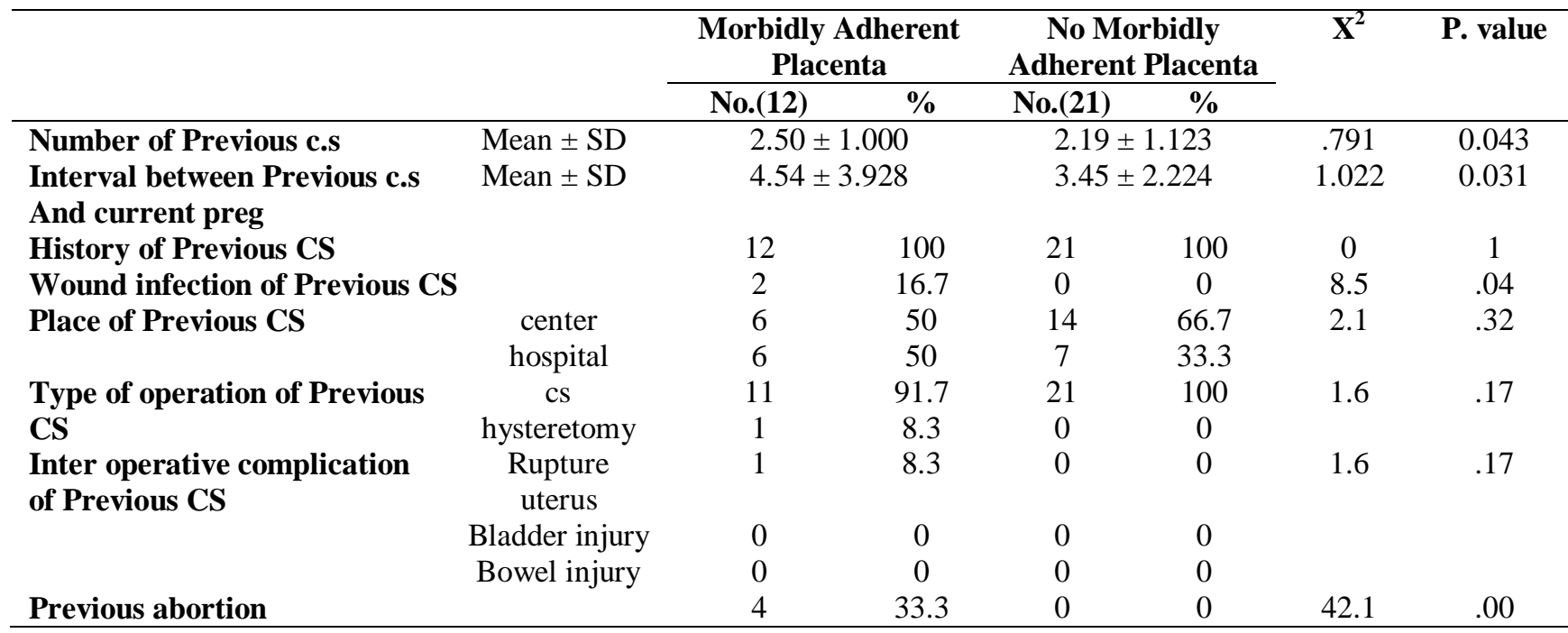

Table (7) Comparison between cases with Morbidly Adherent Placenta and cases without Morbidly Adherent Placenta regarding Blood transfusion (numbers of packs of blood) and Investigation.

\begin{tabular}{|c|c|c|c|c|c|c|}
\hline & & & $\begin{array}{c}\text { Morbidly } \\
\text { Adherent Placenta }\end{array}$ & $\begin{array}{c}\text { No Morbidly } \\
\text { Adherent Placenta }\end{array}$ & $\mathbf{X} 2$ & P. value \\
\hline $\begin{array}{l}\text { Blood transfusion } \\
\text { (numbers of packs of } \\
\text { blood) }\end{array}$ & \multicolumn{2}{|c|}{ Mean \pm SD } & $2.92 \pm 1.929$ & $0.86 \pm 1.352$ & 3.600 & 0.001 \\
\hline Hb $(g / d l)$ & \multicolumn{2}{|c|}{ Mean $\pm \mathrm{SD}$} & $10.11 \pm 0.784$ & $8.98 \pm 0.839$ & 3.915 & 0.000 \\
\hline \multirow[t]{2}{*}{ RH } & Negaitive & $\begin{array}{c}\text { No. } \\
\%\end{array}$ & $\begin{array}{c}1 \\
8.3 \%\end{array}$ & $\begin{array}{c}2 \\
9.5 \%\end{array}$ & .013 & 0.909 \\
\hline & Positive & $\begin{array}{c}\text { No. } \\
\%\end{array}$ & $\begin{array}{c}11 \\
91.7 \%\end{array}$ & $\begin{array}{c}19 \\
90.5 \%\end{array}$ & & \\
\hline
\end{tabular}




\section{Discussion}

This examination demonstrated that, level of Morbidity Adherent Placenta was (36.4\%).These outcomes concurred with A. Fox Karin et al. [9] who detailed that, The frequency of MAP is rising significantly because of increment in the pace of cesarean conveyance, it was as high as 1 out of 20 pregnancies in ladies with both placenta previa and earlier cesarean conveyance.

The danger of placental anomalies increments within the sight of uterine scars because of cesarean conveyance or gynecologic methodology, for example, curettage, myomectomy and hysteroplasty, additionally in cutting edge maternal age and multiparity [10].

K.E. Fitzpatrick et al. [2] who expected to appraise the occurrence of placenta accreta and depict hazard factors, clinical practice and perinatal results. Casecontrol concentrate in Australia and New Zealand. They assessed the occurrence in the UK to be 1.7 per 10,000 maternities generally. Be that as it may, the frequency is extensively higher in ladies with both a past cesarean conveyance and placenta praevia, happening in around one in each twenty such ladies.

S. El Gelany et al. [11] who found that, the rate of PAS issue during the investigation time frame [9].

Various variables may represent these distinctions. There is no accord clinical definition for placenta accreta/increta/percreta, the highest quality level being obsessive analysis, which is unmistakably just pertinent to situations where hysterectomy has been performed. Different examinations, especially those depending on routinely coded information, might not have utilized such a thorough clinical definition, including bogus positive cases. Other methodological contrasts may represent our lower occurrence gauges. The current writing comprises predominately of studies embraced utilizing review audit of clinical records over various years in a solitary or modest number of emergency clinics.

This examination demonstrated that, the level of Accreta (18.2\%), Focal Accreta (3.0\%), Percreta (15.2\%).These outcomes concurred with M. Ahmed Gharib et al. [12] who found that, most pervasive sullen bond was accumulate by a percent of $62.5 \%$.

In an investigation by Farah Nasrullah et al [13] they revealed the accompanying occurrences of anomalous placentation: placenta accreta in (69.6\%) of ladies, placenta increta in (13\%) and placenta percreta in $(17.4 \%)$.

This examination demonstrated that, there were measurably critical increment in Number of Previous CS among cases with Morbidly Adherent Placenta than cases without Morbidly Adherent Placenta.This concurred with K.E. Fitzpatrick et al. [2] who discovered placenta accreta/increta/percreta were additionally brought up in ladies who had a past cesarean conveyance. There seem, by all accounts, to be a direct relationship between placenta accreta/increta/percreta and number of past cesarean conveyances, with ladies who had at least two past cesareans having comparable chances of placenta accreta/increta/percreta to ladies with one past cesarean.

In the current examination, there were factually critical increment in Gravidity (frail) and Parity and maternal age among cases with Morbidly Adherent Placenta than cases without Morbidly Adherent Placenta. These outcomes concurred with numerous creators K.E.Fitzpatrick et al. [2] who read chance variables for PAS issue and found that high maternal age, earlier cesarean conveyance and placenta previa were considered as huge hazard factors.

Likewise, another investigation in 2017 revealed that more established maternal age, earlier cesarean area, placenta previa and high equality were autonomous hazard factors for PAS issue [14].

In the current examination, there was no measurably critical distinction between cases with Morbidly Adherent Placenta and cases without Morbidly Adherent Placenta in regards to BMI.

This can't help contradicting C.M. Farquhar et al. [14] who discovered ladies with placenta accreta were bound to, have a higher BMI.

In the current investigation, there were measurably huge abatement in hemoglobin among cases with Morbidly Adherent Placenta than cases without Morbidly Adherent Placenta.

These outcomes concurred with M. Ahmed Gharibet al. [12].

In the current investigation, luckily, no mortality was found. This aggress with S. El Gelany et al. [11] who didn't report any mortality in their study.It has been accounted for that the death pace of PAS issue was roughly $7.0 \%$ [15].

So also, an ongoing report in Egypt found that death rate in PA cases was 3.2\% [16].

\section{Conclusion}

From this investigation, it could be closed that:Women with an earlier cesarean conveyance had a high frequency of MAP. The most common bleak attachment was placenta accumulate. Expanded rate of MAP with expanding number of past cesarean conveyances. There was additionally an expanded danger of MAP related with more established maternal age. Multiparity and multigravidas have been proposed as being related with a higher danger of MAP.

\section{References}

[1] N.Tahir, M.Adil, B.Afzal , Definitive management of morbidly adherent placenta: analysis of maternal outcomes. Pak Armed Forces Med J, Vol.68 (5)PP. 1156-1160,2018.

[2] K.E. Fitzpatrick, S. Sellers, P. Spark, Incidence and risk factors for placenta accreta/increta/percreta in the UK: a national case-control study. PLoS ONE, Vol.7(12), PP. e52893,2012.

[3] L. Sentilhes, G. Kayem, E. Chandraharan , FIGO placenta Accreta diagnosis and management expert consensus panel. FIGO consensus guidelines on placenta accreta spectrum disorders: 
conservative management. Int J Gynaecol Obstet, Vol.140(3), PP.291-8,2018.

[4] Z.S. Bowman, A.G. Eller, T.R. Bardsley, Risk factors for PAS disorders: a large prospective cohort. Am J Perinatol,Vol.31, PP.799-804,2014.

[5] E.R.M. Jauniaux, Z. Alfirevic, A.G. Bhide, on behalf of the Royal College of Obstetricians and Gynaecologists. Placenta Praevia and Placenta Accreta: diagnosis and management: green-top guideline No. 27a. BJOG, Vol.126(1), PP.e1e48,2019.

[6] J.P. Lerner, S. Deane, I.E. Timor-Tritsch, Characterization of placenta accreta using transvaginal sonography and color Doppler imaging. Ultrasound Obstet Gynecol, Vol.5, PP. 198 - 201,1995.

[7] C.H. Comstock (): Antenatal diagnosis of placenta accreta: A review. Ultrasoud Obstt Gynecol , Vol.26, PP. 89-96,2005.

[8] K.K.P. Benirschke, P. Kaufmann Pathology of the human placenta, 4th edn. New York: Springer,Vol.10(9), PP.3025,2000.

[9] A. Fox Karin, A. Shamshirsaz Alireza, Daniela Carusi , Conservative management of morbidly adherent placenta: expert review. American Journal of Obstetrics \& Gynecology.; Volume 213, Issue, Vol.6, PP. 755-760,2015.

[10] L.ia Valentini Anna, Benedetta Gui, Valeria Ninivaggi, The morbidly adherent placenta: when and what association of signs can improve MRI diagnosis? Our experience. Diagn Interv Radiol, Vol. 23, PP. 180-186,2017.
[11] S. El Gelany, M. H. Mosbeh, E. M. Ibrahim, Placenta Accreta Spectrum (PAS) disorders: incidence, risk factors and outcomes of different management strategies in a tertiary referral hospital in Minia, Egypt: a prospective study. BMC pregnancy and childbirth,Vol. 19(1),PP. 313,2019.

[12] M. Ahmed Gharib, W. Mohamed El-Nagar, M. ElBakry Lashin, 'EVALUATION OF PROTOCOL OF MANAGEMENT OF MORBIDLY ADHERENT PLACENTA IN MATERNITY ZAGAZIG UNIVERSITY HOSPITAL ', Zagazig University Medical Journal,Vol. 25(3), PP. 481489,2019.

[13] Farah Nasrullah, Ayesha Khan, Shamim Haque , Review of cases of morbidly adherent placenta in a tertiary care unit. MC, Vol. 22,PP. 43-47,2016.

[14] C.M. Farquhar, Z.Li , S. Lensen, Incidence, risk factors and perinatal outcomes for PAS disorders in Australia and New Zealand: a case-control study. BMJ Open,Vol.7, PP.e017713,2017.

[15] D. Zhang, Y. Siqin, H. Yanyan, Risk factors, outcome and management survey of PAS disorders in 153 cases: a five-year experience from a hospital of Shanghai, China. Int J Clin Exp Med,Vol.10(8), PP.12509-16,2017.

[16] M.S. Zakherah, M. Abdel-Aziz, E.R. Othman, Maternal and neonatal outcomes of placenta previa and accreta at Assiut women's health hospital, Egypt. Int J Reprod Contracept Obstet Gynecol,Vol.7(8),PP.3024,2018. 